\title{
Cómo grita la tipografía. Procesos de mediación cultural y condición de lo visible
}

\author{
How typeface shouts: Cultural mediation processes and the state of that which \\ is visible
}

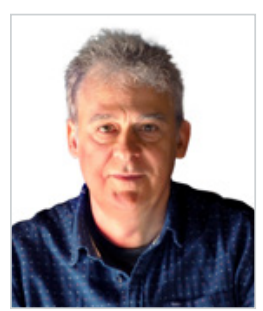

Mario F. Benito Cabello. Profesor asociado de la Facultad de Ciencias de la Comunicación de la Universidad Rey Juan Carlos (URJC) y doctorando en el Programa de Ciencias Sociales y Jurídicas de la URJC. Es licenciado en Periodismo por la Universidad Complutense de Madrid y Máster en Periodismo Cultural y Nuevas Tendencias por la URJC. Sus líneas de trabajo son el diseño periodístico, la tipografía, el periodismo y la comunicación visual. Ha trabajado como diseñador periodístico entre 1990 y 2016 en diversos periódicos nacionales y de ámbito local (El Mundo, El Sol, Marca, La Información de Madrid) y en revistas (Grupo Z). Es coeditor del sitio web www.encajabaja.com sobre prensa y diseño periodístico (referencia incluida en guías docentes universitarias), ha participado como jurado en los premios SND españoles y como conferenciante en distintos congresos (Universidad Pontifica de Salamanca, Universidad CEU San Pablo de Madrid y en la URJC).

Universidad Rey Juan Carlos, Madrid, España

mario.benito@urjc.es

ORCID: 0000-0002-3409-7563

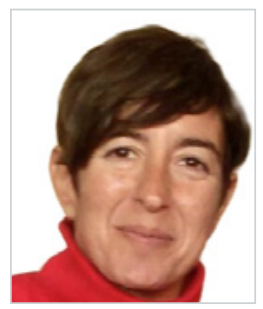

Ma José Sánchez Leyva. Profesora e investigadora de la Facultad de Ciencias de la Comunicación de la URJC Sus líneas de trabajo son la semiótica y el análisis del discurso, la ética y la filosofía políticas, la comunicación y las representaciones colectivas y el feminismo. Ha participado en múltiples congresos, seminarios nacionales e internacionales, cursos y talleres como docente y conferenciante. Ha organizado, coordinado y dirigido múltiples encuentros científicos. Lleva más de 20 años de docencia y de investigación ininterrumpida y es autora de distintas publicaciones. Pertenece al grupo UCM Cultura visual: imagen, información y discurso. Su trabajo estos últimos años está centrado en los procesos de subjetivación contemporáneos como instrumentos de control social.

Universidad Rey Juan Carlos, Madrid, España

mariajosefa.sanchez@urjc.es

ORCID: 0000-0003-4915-226X

Recibido: 16/11/2018 - Aceptado: 26/03/2019

\section{Resumen:}

Cada discurso se entrelaza en una compleja red de otros discursos, instituciones, prácticas de poder y producción simbólica cuya importancia es decisiva en la configuración de lo social. El cuerpo de dichos discursos es el objeto de esta propuesta que reflexiona sobre el carácter mediador de la tipografía y ejemplifica, con el uso de los caracteres góticos durante el nazismo y previamente la lucha entre caracteres góticos frente a romanos en el Renacimiento,

\section{Received: 16/11/2018 - Accepted: 26/03/2019}

\section{Abstract:}

Every discourse is intertwined in a complex network of other discourses, institutions, power relations, and symbolic production, the importance of which is decisive in shaping the social realm. The bodies of these discourses are the object of this study, which reflects on the mediation feature of typefaces. Through an analysis of the use of Blackletter characters during the Nazi period and the previous struggle between Blackletter and Roman characters during

Cómo citar este artículo:

Benito Cabello, M. F. y Sánchez Leyva, Ma J. (2019). Cómo grita la tipografía. Procesos de mediación cultural y condición de lo visible. Doxa Comunicación, 28, pp. 133-150. 
la operación cultural de las formas de visualización en la era digital. El impacto de las tecnologías de la información afecta a la construcción del imaginario moderno, con el que la modernidad justifica su propia dinámica, su trama cultural y cognitiva, su formación histórica. La tipografía es un elemento central de ese imaginario contemporáneo y, en tanto signo, se convierte en el escenario de la lucha entre diferentes definiciones y significados: una lucha por la posesión del signo que se extiende hasta las áreas más triviales de la vida cotidiana. Es por eso que el tipo grita.

\section{Palabras clave:}

Tipografía, mediación, imaginarios, forma y contenido, comunicación visual. the Renaissance, the research exemplifies the cultural processes involved in forms of visualization in the digital age. The impact of information technology affects the creation of the modern collective imaginary which modernity uses to justify its own dynamic, its cultural and cognitive narratives, and its historical development. Typography is a central element of this contemporary collective imaginary, and while it is a sign, it becomes the setting for the struggle between different definitions and meanings: a battle for the possession of the sign that extends to the most trivial areas of everyday life. That is the reason why typeface shouts.

\section{Keywords:}

Typography, mediation, social imaginary, form and content, visual communication.

\section{Introducción y presentación: la tipografía como dispositivo cognitivo}

Steve Jobs en su célebre discurso pronunciado en la Universidad de Stanford en 2005 destacó la importancia que tuvo la tipografía en el posterior desarrollo de los ordenadores Apple - “y como Windows no hizo más que copiar los Mac”, ahora todos los ordenadores deben en parte cómo es su interfaz a la tipografía-:

En aquella época la Universidad de Reed ofrecía la que quizá fuese la mejor formación en caligrafía del país (...) Aprendí cosas sobre el serif y tipografías sans serif, sobre los espacios variables entre letras, sobre qué hace realmente grande a una gran tipografía. Era sutilmente bello, histórica y artísticamente (...) y lo encontré fascinante. Nada de esto tenía ni la más mínima esperanza de aplicación práctica en mi vida. Pero diez años más tarde, cuando estábamos diseñando el primer ordenador Macintosh, todo eso volvió a mí. Y diseñamos el Mac con eso en su esencia. Fue el primer ordenador con tipografías bellas (...) Y como Windows no hizo más que copiar el Mac, es probable que ningún ordenador personal los tuviera ahora. Si (...) no hubiera entrado en esa clase de caligrafía, los ordenadores personales no tendrían la maravillosa tipografía que poseen (Jobs, 2005).

La "maravillosa tipografía”... y todo el actual potencial gráfico. Porque fue necesario que quienes desarrollaron aquellos primeros ordenadores personales -tanto en el software de sus sistemas operativos, como en el hardware de sus tarjetas gráficas y procesadores capaces de codificar imágenes de muy alta resolución- trataran las tipografías como imágenes para poder representarlas con la precisión que Jobs deseaba. Esto orientó el desarrollo de los ordenadores en una dirección concreta: las representaciones visuales (escritorios, windows, iconos... letras exactas). Es un claro ejemplo de la importancia de la tipografía no como conjunto de signos alfabéticos sino como imágenes en sí. Parece claro que para la función básica de los caracteres como signos de un alfabeto no haría falta en realidad más que una tipografía y sería absurda la creciente variedad existente; es evidente, pues, que disponemos de diferentes tipos de letra porque cada uno expresa algo distinto, aunque tampoco olvidamos la necesidad de distintos tipos de letra en función de la técnica de reproducción, del soporte en el que van a ser dispuestos, impresos o en pantalla, o bien en función del tamaño de los propios caracteres, según indican autores como Enric Jardí (2007: 12, 64). El vínculo entre tipografía y tecnología, cómo la primera está unida indisoluble- 
mente al desarrollo tecnológico, permite observar no sólo cómo la tipografía es uno de los elementos fundamentales de la cultura visual sino la manera en la que se producen los procesos de mediación cultural con la tecnología que la posibilita. El objetivo de esta propuesta es reflexionar sobre el carácter mediador de la tipografía y ejemplifica, con el uso de los caracteres góticos durante el nazismo y previamente la lucha entre caracteres góticos frente a romanos en el Renacimiento, la operación cultural de las formas de visualización en la era digital. El hecho de que se asocie cierto contenido a un signo, entendiendo que el signo es a su vez forma y contenido, implica el esfuerzo de explicar el funcionamiento de los elementos de la significación: presencia, intención y motivación, en la consideración barthesiana. A partir del análisis de estos ejemplos, se trata de poner de manifiesto cómo las estrategias visuales-estéticas, de puesta en imagen y de conformación de la mirada (tres dimensiones diferentes pero interrelacionadas) operan hoy la mediación de lo social. Teniendo en cuenta, aunque no lo tematicemos, que la tipografía desde sus características visuales desarrolla una función comunicativa y estética que, además de permitir el proceso de lectura, puede generar significaciones que de cierta forma favorecen la interpretación de un texto.

La hipótesis de trabajo es que la realidad visual no es innata ni inevitable, todo lo que vemos puede adoptar una forma distinta, por lo que detrás de lo que se ve hay otras muchas posibilidades visibles que han sido rechazadas. Los motivos de la elección tipográfica -diálogo entre presencia y ausencia- nos hablan de que la condición de lo visible es arbitraria y los modos de presentar lo existente y sus representaciones nunca son completos y obedecen a operaciones simbólicas de producción de sentido que realizan lo social. La tipografía, entonces, forma parte de los imaginarios sociales contemporáneos.

Para desarrollar los objetivos propuestos, en coherencia con la naturaleza exploratoria de este trabajo, se ha optado por una metodología basada, por un lado, en la revisión bibliográfica que, por la propia naturaleza de un artículo, no puede ser exhaustiva pero sí rigurosa y trabajada. Y, por otro, hemos realizado un análisis de dos tipografías, selección que ha permitido ilustrar las consideraciones teóricas; consideraciones que, a su vez, han sido propiciadas por ellas. En este trabajo se revisan diferentes perspectivas teóricas que se enmarcan en la semiótica, no tanto para sostener posturas cerradas como para realizar una reflexión rigurosa sobre las aportaciones que desde diferentes ámbitos se realizan sobre nuestro objeto de estudio. La constatación de que los signos vehiculan ideas sobre el mundo, hacen circular sentidos y éstos suponen modelos y esquemas de organización del conocimiento que representan "directrices ideológicas", es decir, representaciones que conforman una determinada visión del mundo nos llevó a adoptar esta perspectiva como orientación teórica y metodológica.

\section{La tipografía como grafema}

Tipografía es un término polisémico que se refiere a diferentes aspectos de las artes gráficas. En primer lugar, puede entenderse como el diseño completo de una publicación, la correcta disposición de los elementos en la página así como la elección de los tipos de letra, tal y como precisó Stanley Morison en su ya clásica definición incluida en la Encyclopaedia Britannica publicada en Londres y Chicago en 1929, y que sigue apareciendo hasta el día de hoy:

La tipografía puede definirse como el arte de disponer correctamente el material de imprimir de acuerdo con un propósito específico: el de colocar las letras, repartir el espacio y organizar los tipos con vistas a prestar al lector la máxima ayuda para la 
comprensión del texto. La tipografía es el medio eficaz para conseguir un fin esencialmente utilitario y sólo accidentalmente estético, ya que el goce visual de las formas constituye rara vez la aspiración principal del lector (Morison, 1998: 95).

Jan Tschichold, uno de los tipógrafos más importantes e influyentes del siglo XX, impulsor de la 'Nueva tipografía' (Die Neue Typographie) surgida en Alemania en la década de los años 20 del siglo pasado y que promulga los mismos principios "funcionalistas" de la Bauhaus en lo relativo a la claridad y a que "la forma sigue a la función”, entiende también la tipografía de esta forma global, a la que él llama "arte de la escritura": "Los tipos buenos, la disposición correcta: estos son los dos pilares de todo el arte de la escritura” (Tschichold, 2002: 25).

Además de la composición y elección de elementos (el diseño global), con tipografía nos referimos también al sistema de composición de textos anterior a los procedimientos mecánicos o digitales del presente, así como a un sistema de impresión utilizado de forma general hasta su actual sustitución por la tecnología denominada offset. La impresión tipográfica es directa, en ella el molde o plancha en relieve se transfiere plano contra plano al soporte (papel, etc.), mientras que el offset es un sistema de impresión indirecto (del molde o plancha a un cilindro de goma y de ahí al soporte final) y planográfico (basado en la xilografía), es decir sin que exista relieve en las planchas (Bann, 2008).

En tercer lugar, tipografía es también el arte de diseñar tipos de letras, exclusivamente. Un tipógrafo, en sentido estricto, es la persona que crea alfabetos, que los dibuja elaborando previamente un boceto a mano y que, antes de la tecnología digital, grababa unos punzones con los que después se elaboraban las matrices de las que saldrían los famosos tipos móviles de plomo y que ahora utiliza un software de edición tipográfica para crear archivos informáticos en los que están codificados cada uno de los tipos de letra y sus variantes. El Manual de la Imprenta Española o Arte de la Imprenta de Antonio Serra y Oliveres, publicado en Madrid en 1852, distingue entre "tipógrafo", que sería "quien ejerce la ciencia o el arte de la imprenta”, en el sentido global expuesto por Morison, y "tipografista”, persona que "hace experimentos o busca perfeccionar el arte de la imprenta” (Serra y Oliveres, 1852: 266), en el que podemos encuadrar al diseñador o creador de nuevos tipos de imprenta. Este último término no se usa en la actualidad y para distinguir estas dos facetas, utilizamos el término de "tipógrafo" para la persona que diseña nuevos tipos de letras, nuevas tipografías -que es el cuarto aspecto al que se refiere el término, como sinónimo de un tipo de letra-, y “diseñador gráfico” para quien trabaja con tipografía, compone textos en función de los valores semánticos y pragmáticos que conlleva la elección de una tipografía, es decir un tipo de letra, para su utilización en una publicación determinada.

En último lugar, como acabamos de mencionar, el término tipografía se utiliza actualmente tal vez de un modo no del todo ortodoxo, pero cada vez con mayor frecuencia, para denominar al conjunto de tipos de letra de una publicación, e incluso a un tipo de letra concreto. Así utilizamos una "tipografía” determinada en vez de utilizamos un "tipo de letra”. Este uso de tipografía asimilado a tipo de letra se da sobre todo entre los profesionales de una forma que está ampliamente admitida. Así lo hacen Laura González y Pedro Pérez Cuadrado en sus Principios básicos sobre diseño periodístico: "El primer paso de un trabajo de diseño gráfico - de cualquier especie: libro, revista, diario, cartel, folleto o página web- pasa por la elección de la tipografía con la que pretendemos comunicar el mensaje" (2001: 77).

Es en esta última acepción de la tipografía, entendida como un tipo de letra, en la que vamos a centrarnos como un elemento de mediación cultural. Un elemento gráfico que no sólo es un signo en un sistema de escritura al que se asocia ar- 
bitrariamente un sonido para formar después palabras con un significado (en ese caso, no existirían distintas tipografías). No hablamos de letras, pues, sino de tipografías, como bien distingue Enric Satué:

En cierto modo [la propuesta de su libro Arte en la tipografía y tipografía en el arte] es una invitación a leer. Evidentemente, no letras, sino tipografías; es decir, no los contenidos sino las formas y estilos con que se vienen manifestando los textos tipográficos desde hace más de quinientos años, aspirando a estimular el conocimiento de la lúcida advertencia de Joyce:

"No es lo mismo una palabra vista que oída" (2007: 13).

Frente a la dicotomía establecida entre imagen y palabra, la tipografía es una combinación indisoluble de ambas y su correcta elección dependerá de que ambos, el significado del texto compuesto con un tipo de letra, y lo que transmite la forma, el grosor, el equilibrio, la armonía del dibujo de los caracteres, estén en sintonía. La búsqueda de coherencia decide pues la elección del tipo para que el sentido así producido no contradiga el significado. No se trata entonces sólo de lo resumido en el clásico de Dondis "una combinación de lo verbal y lo visual en un intento directo de transmitir información" (2004: 188) sino de un problema de sentido. Roberto Gamonal, profesor de diseño gráfico y análisis de la imagen en la Universidad Complutense, además de tipógrafo, habla de una "retórica tipográfica" con fines persuasivos para incitar a su lectura y para generar sentido o potenciar el significado textual: "los caracteres pueden transmitir no sólo información textual, sino también múltiples sensaciones a través de su forma" (Gamonal, 2012: 79). El problema de la tipografía que planteamos es pues que se trata de un tipo de comunicación visual que rebasa la dimensión lingüística. Así, la forma de las letras, sus terminaciones, su dimensión, el contraste entre trazos y su modulación se convierte en elemento fundamental ya que más allá de permitir la representación de la lengua, comunican y logran que los destinatarios experimenten su relación con la escritura de forma distinta a la experiencia producida en la recepción del signo lingüístico. Artistas, diseñadores tipográficos y poetas han abordado precisamente por esto el problema semiótico en la tipografía. Solo tenemos que aproximarnos a los poemas de Mallarmé y Apollinaire o a los poemas visuales de Joan Brossa, por ejemplo. Lo interesante de esta aproximación es que nos permite abordar los procesos de mediación cultural y los modos de construcción del sentido compartido en los imaginarios sociales.

\section{El cuerpo de la mediación cultural}

Pensamos, con Abril (1997: 63), que "los modos histórico-culturales del conocer y comunicar suponen las formas específicas de producir, manipular e interpretar signos y textos. Así, se puede hablar de distintos regímenes semióticos para referirse a las actitudes respecto a los signos y textos que caracterizan las prácticas culturales de distintas sociedades". Desde esta perspectiva, para el autor, esta combinación de lo lingüístico y lo visual propia del "espacio tipográfico" en tanto técnica de los tipos móviles y los signos "vehiculados, procesados o inscritos por la imprenta" se inscribe dentro de lo que denomina "espacio sinóptico" al conceptualizarlo, tal como hacemos en estas páginas, como "forma cultural y cognitiva". Para Abril, sinóptica es la experiencia de "ver a la vez de una ojeada", experiencia visual "sincrónica de un conjunto textual que no era posible con los discursos temporalizados de la narración y de la oratoria” (2003: 108). Es la experiencia primera de ver una página compuesta de una forma determinada y con unos tipos de letra concretos antes de su lectura o, de una forma más precisa aún, a la vez que se lee ("sincrónica"). Y es con la imprenta y la tipografía con la que nace este "espacio sinóptico": 
Un cambio formidable se produjo en la historia de las prácticas semióticas cuando a la lógica propiamente lingüística se añadió, ya en los libros medievales, pero sobre todo a partir de la imprenta, una nueva lógica determinada por la presentación visual de las palabras, por su distribución en el espacio bidimensional de la página y en el espacio tridimensional del volumen, y por su combinación con otras clases de signos gráficos e icónicos (...) El libro no es, como suele pretender el canon logocéntrico, un artefacto lingüístico, sino una compleja máquina visual (Abril, 2003: 107).

Máquina visual que activa la tipografía. Indagar entonces en la especificidad que hace de la tipografía una forma cultural y cognitiva nos permitirá atender a los procesos de construcción de lo social. Nuestros ejemplos, pensamos, servirán a tal fin. La mediación es la capacidad de ciertas instancias de organizar la experiencia del mundo que tenemos los sujetos. Estas instancias proponen una serie de discursos que situándose entre el sujeto y el mundo orientan la visión que este sujeto tiene de la realidad social. Es decir, se movilizan discursos que articulan universos simbólicos y que intervienen organizando nuestra experiencia de la realidad. Estos discursos subyacentes necesitan un cuerpo para encarnarse y poder funcionar como mediadores; una forma que siempre es necesaria pero también diversa, la tipografía es un ejemplo. Basta apelar a la experiencia banal y cotidiana de seleccionar un tipo de letra cuando deseamos comunicarnos con diferentes interlocutores. No es lo mismo la tipografía seleccionada para dirigirnos a una institución que a un amigo. De la misma manera esto explica por qué muchas veces rehuimos o abandonamos el uso de cierto tipo, como por ejemplo la Comic sans, que parece haber muerto de éxito. Es claro que la forma de decir afecta lo dicho; en nuestros términos, que la forma es un elemento significante que implica también un significado. Significado que vinculado al del signo que corporeiza colabora en la producción del sentido. Nuestro ejemplo sobre el vínculo entre cierta tipografía y el nazismo creemos que es muy esclarecedor a este respecto.

El alcance de este planteamiento sobre los gritos tipográficos va más allá de una mera consideración metodológica sobre el funcionamiento del sentido y se dirige a un planteamiento epistemológico: la realidad no es inmune a las racionalidades e interpretaciones llevadas a cabo por los agentes sociales en sus interacciones. Lo que aparece, lo que nos es dado, aquello con que nos configuramos las certezas de saber algo sobre el mundo no constituyen exclusivamente lo real. Contra la ingenua absolutización de lo existente proyectada por el empirismo y el positivismo, los hechos no son algo simplemente dado o natural sino el resultado de una situación social que, por su misma naturaleza, han sido intersubjetivamente formados y están entonces siempre disponibles para seguir siendo formados o transformados. Definir lo real como equivalente a lo existente es una forma de poder que no se ejerce sólo por la imposición de la fuerza, sino a través de la creación y el mantenimiento de un espacio simbólico, un ámbito de sentidos socialmente compartidos en el que todos podamos reconocernos sin conflicto. Por ello, insistimos, no hay realidad plenamente inmune a las interpretaciones, marcos y racionalidades construidos por los actores sociales en su interacción; ni completamente distinta de las articulaciones y categorizaciones lingüístico-discursivas a través de la que es objetivada. La tipografía es ese cuerpo, una objetivación que expresa una concepción del mundo o implica unos relatos sobre el mundo que son movilizados con su uso. Precisamente esto determina su elección, sabemos que no remitimos a la misma consideración del mundo si usamos la gótica o la romana.

Reinhard Gäde -diseñador gráfico creador del diseño original del diario El País en 1976 junto a Julio Alonso y Fermín Vílchez- relataba a gritos a los asistentes a las VI Jornadas de Diseño Periodístico de la Universidad CEU San Pablo, celebradas en Madrid en mayo de 2001, cómo “ila tipografía puede gritar! Puede susurrar, hablar en voz baja...”. Los organizadores 
de las Jornadas, Pedro Pérez Cuadrado y Laura González Díez, recogen con más detalle las palabras de Gäde en aquel encuentro en el que detalló su proyecto para el mencionado diario, "un diseño que creó escuela y fue imitado por numerosos medios impresos” de España (Vílchez, 2011: 454), e incluso europeos:

Consideramos que en ese momento, si el periódico [El País] hubiera dicho cualquier barbaridad para las sensaciones franquistas, que todavía existían, en una Times cursiva de 36 puntos se vería como una barbaridad muy elegante e incluso muy justa. Pero si decías las mismas palabras en letras Helvética o Futura -como lo hizo después un periódico del grupo de Juan Tomás de Salas gritando ¡Libertad!-, a nosotros nos cerraban en dos o tres semanas y se acababa el asunto (González Díez y Pérez Cuadrado, 2007: 37).

La vida humana tiene lugar en un múltiple ecosistema que Lotman denomina semiosfera y que representa el conjunto de los significados, de los textos, de los repertorios de signos y de las traducciones de unos signos a otros que constituyen el medio en que se desarrolla la existencia de los seres humanos en tanto seres semióticos. Por ello, decir las mismas palabras en tipos distintos hace que ya no sean las mismas palabras. Puede entenderse entonces que la tipografía es uno de esos ámbitos que expresan cómo la sociedad humana se ordena simbólicamente, a través de categorías, representaciones, relatos e imaginarios comunes. Esto es lo que lleva al Grupo $\mu$ a denominar a los signos tipográficos "grafemas" en tanto que son portadores de significación (1987:100).

Podríamos entonces sostener que la tipografía expresa un fenómeno de indicación, identificación y acotación de lugares simbólicos. Supone uno de los mecanismos por los que las sociedades integran y contienen los acontecimientos en sistemas convencionales de creencias y conocimientos que permiten el reconocimiento inmediato de las representaciones comunes como vinculadas naturalmente a un orden social estable y colectivo. Es, entonces, portadora de una determinada racionalidad que posee un valor para una comunidad determinada: el de demarcar un territorio simbólico en relación con otros posicionamientos discursivos.

La interpretación pues de esta máquina visual, con las características mencionadas, compromete a una determinada comprensión del mundo. Su modo de significar permite que la tipografía pueda experimentarse como problema semiótico, y lo primero que ha de hacerse es no naturalizarla para evidenciar el hecho de su naturaleza socio-discursiva. Sólo así dejará de ser considerada como un mero soporte más o menos eficaz o bello que es simple reflejo unánime del significado del signo o, peor, del mundo al que refieren. El relato que entraña el tipo de tipo es producto de una historia, supone una condensación de saber, exhibe una orientación y expresa un punto de vista. Por ello suponen, como dijimos más arriba, el lugar de una elección.

La asunción de que el sentido es un modo de donación del referente que contiene indicaciones, ha sido desarrollada por la filosofía analítica de raíz fregeana y por la filosofía del lenguaje ordinario inspirada en Strawson. La semiótica y el Análisis del Discurso enunciacional asume, decantándose en el debate por Strawson, que decir es un acontecimiento discursivo por el que lo que es dicho no es independiente del hecho de decirlo. La perspectiva enunciacional incorpora las consideraciones austinianas y de Benveniste por las que todos los signos proporcionan indicaciones que conciernen al hecho de su enunciación, y estas indicaciones forman parte de su sentido. Pero la mayor parte de las perspectivas teóricas consideran estas indicaciones como informaciones accesorias o complementarias del decir, marginando lo mostrado. Sólo la prag- 
mática las ve necesarias pero exclusivamente en lo que atañe a la determinación del tipo de acto. La semiótica estructural también se debate sobre la naturaleza de estas indicaciones, reconociéndoles su importancia para la determinación del sentido. Por ello, pensamos que son precisos en el análisis del sentido instrumentos para pensar cómo estas singularizaciones se convierten en hábitos interpretativos, es decir, cómo las indicaciones devienen necesarias. Desde este punto de vista vemos sumamente útil la propuesta metodológica de Farias para poder llevar a cabo análisis que den cuenta de lo anterior. La autora sostiene que:

\begin{abstract}
Cruzando estes níveis, e a partir da interpretação da semiótica peirceana feita por Charles Morris, o quadro de análise aqui proposto é completado pelas dimensões sintática, semântica e pragmática dos artefatos analisados. A dimensão sintática diz respeito aos aspectos formais ou denotativos da tipografia, notadamente aqueles vinculados à sua visualidade, estrutura e comportamento. A dimensão semântica refere-se aos aspectos denotativos da tipografia, ou aos significados atribuídos (socialmente, historicamente, estrategicamente), às formas tipográficas. A dimensão pragmática deve ser entendida aqui, em consonância com o pensamento de Charles S. Peirce , como a soma das conseqüências práticas (materiais e ambientais, mas também culturais, sociais e econômicas) resultantes da concepção e uso da tipografia (Farias, 2016: 47).
\end{abstract}

No es este el lugar para proponer un modelo de análisis que permita formalizar los movimientos y orientaciones de significación, pero no queríamos dejar de señalar cómo los fenómenos que abordamos desde un punto de vista especulativo tienen su anclaje en el funcionamiento real de los textos.

El concepto de tipografía permite, pues, reflexionar sobre un aspecto determinante: lo que el signo muestra es imprescindible para la configuración del sentido en igual medida que lo es el significado. Además, esas indicaciones elaboran o suponen un filtro porque cuando un signo indica, centra la mirada sobre algún aspecto del objeto designado. Este modo de significación propone una determinada memoria, unas asociaciones de sentido concretas y unas orientaciones prospectivas determinadas que habitúan una interpretación. Y estas consideraciones acerca del funcionamiento del signo permiten reinterpretar la consideración tradicional acerca de las relaciones entre lenguaje y contexto, signo y mundo. La representación que la tipografía ofrece a la interpretación es producto de un proceso inferencial orientado, que expresa un punto de vista sobre el objeto y los contenidos vehiculados.

\title{
4. La primera batalla (Gótica versus romanas)
}

Tendemos a pensar que vivimos en tiempos acelerados, una época nueva y distinta a todas las anteriores en la que se suceden sin interrupción los cambios y los acontecimientos mucho más rápido que incluso la capacidad para asimilarlos, en contraste con un pasado idealizado en el que las cosas acontecían despacio y los cambios sociales eran cosa de siglos y no de décadas, tal y como los medidos ahora. Pero si pensamos en la forma en la que se transformó Europa entre 1450 -en 1449 Gutenberg imprime su Misal de Constanza, la primera obra impresa con tipos móviles en el mundo occidental- y 1500, que es cuando dejan de imprimirse incunables y puede hablarse ya directamente de una industria editorial, tal vez deberíamos revisar entonces el término de aceleración histórica como algo referido exclusivamente al momento actual.

Y es que, según reseña Enric Satué (1998), en apenas esos mencionados cincuenta años y con los medios artesanales de la imprenta recién inventada (había que componer las líneas con los caracteres a mano, uno a uno; imprimir las páginas asî 
formadas una a una; encuadernar a mano, etc.) se habían impreso, y distribuido, nada más y nada menos que más de ocho millones de libros. Thompson va incluso mucho más allá en lo que a las cifras se refiere y citando a Febvre y Martin afirma que estos autores "estiman que a finales del siglo XV se habían producido al menos 35.000 ediciones y se habían puesto en circulación al menos unos 15 o 20 millones de copias". Lo que suponía un porcentaje altísimo en relación a la población total del continente - "algo menos de 100 millones de habitantes en los países en los que se había desarrollado la técnica de la impresión" (Thompson, 2010: 82)-y un cambio cultural de una magnitud sin precedentes, realizado a una velocidad que posiblemente nunca se hubiera visto. "Hacia 1480", prosigue Satué, "había imprentas en 110 ciudades de seis países de Europa”. A pesar del mencionado carácter artesanal de esta actividad, "la impresión con tipos móviles, que reemplazó a la copia manuscrita, fue el primer sistema de producción en serie", tal y como define con acierto Ellen Lupton (2016). Para la autora, "la tipografía es la manifestación visual del lenguaje" y un elemento fundamental en el concepto que tenemos de lo que es un texto, ya que antes de la imprenta los libros estaban llenos de errores que se copiaban de unas copias a otras y fue la tipografía lo que "ayudó a consolidar la noción literaria de texto como un trabajo original y completo, como un cuerpo estable de ideas expresadas de una forma esencial” (2016: 89). Y no sólo eso, en consonancia con Walter Ong hablará además de un cambio en la mentalidad de las personas debido a la manera en que la imprenta estructuró las palabras gracias al espaciado y la puntuación estandarizada, "la escritura lleva las palabras desde el mundo sonoro al mundo del espacio visual, pero la impresión las aprisiona en este espacio".

Este es un problema que Walter Benjamim abordó en 1936, cuando teorizó sobre la "época de la reproductibilidad técnica", sobre los cambios en la forma de pensar que conllevan tanto la mecanización de los últimos dos siglos como la acontecida con los tipos móviles a comienzos del siglo XVI:

Dentro de largos periodos humanos, junto con el modo de existencia de los colectivos humanos, se transforma también la manera de su percepción sensorial. El modo en el que se organiza la percepción humana -el medio en que ella tiene lugarestá condicionado no sólo de manera natural, sino también por la historia (2003: 46).

\section{letraz góticas letras romanas}

Figura 1. Tipografía gótica Fraktur (arriba) y tipografía romana renacentista, o antigua, Bembo (abajo).

Así pues, en este momento histórico preciso en el que nace la reproducción técnica en serie de los textos, se produce lo que podemos llamar la primera batalla de los tipos de letra góticos contra las que desde entonces se constituyen en sus antagonistas y enemigos irreconciliables: las denominadas tipografías romanas. La tipografía llamada gótica en nuestra lengua (Blackletter y Old English en inglés, Fraktur en alemán) engloba a diversos grupos de letras que según la obra de referencia de Bain y Shaw sobre la letra gótica se pueden clasificar en cuatro categorías básicas o estilos: "la gótica de forma (textura o 
gotisch), la gótica de suma (rotunda o rundgotisch), la schwabacher y la gótica de fractura (fraktur)" (2001: 30). La primeras tendrían su origen en el norte de Francia (Bertheau en Bain y Shaw, 2001: 45), y fueron las que sirvieron de modelo a los primeros tipos móviles de Gutenberg, mientras que la schwabacher y la gótica de fractura son "las variantes autóctonas" alemanas (Bain y Shaw, 2001: 31). En su aspecto formal, son tipos de letra que tienen en común unos caracteres compactos y muy angulares, "rasgos diamantados que cierran el ojo del carácter y dificultan en ocasiones su identificación" (Martín Montesinos y Mas Hurtuna, 2007: 50). Los primeros tipos móviles lo que hicieron fue llevar esas letras góticas de origen manuscrito y medieval a las matrices de plomo. Con estos tipos de letra compuso Gutenberg su Biblia de 42 líneas, una obra maestra de la historia de la cultura; pero el maestro impresor de Maguncia:

Sólo pretendía acelerar el interminable proceso que suponía, en aquel momento, la producción manuscrita de un libro (...). Al margen de la novedad del procedimiento, Gutenberg pondrá todo su esmero en que las páginas impresas se asemejen lo más posible a las páginas maestras de los manuscritos, mientras que los tipos metálicos deberán reproducir fielmente los quiebros de la pluma de los caracteres góticos (2007: 51).

Sin embargo, los caracteres góticos se enfrentan ya desde el comienzo al principal de sus problemas: la legibilidad. En sentido estricto, el término se refiere a la mayor o menor facilidad de un texto para ser leído, pero un texto no es lo mismo que un tipo de letra. Existen desde mediados del siglo XX distintos estudios cuantitativos, como los de los pioneros norteamericanos Tinker y Paterson que cita Richaudeau (1984), basados en medir la velocidad de lectura con distintos tipos de letra, tamaños, fondos, etc., y otros más recientes que miden el movimiento ocular. También se han realizado test de comprensión de textos porque es evidente que no es lo mismo leer un texto, más o menos rápido, que comprenderlo. Laura González y Pedro Pérez Cuadrado (2001) reconocen que "el tema de la legibilidad es un poco confuso" y señalan con acierto que en castellano nos referimos con ese mismo término a dos aspectos diferentes que sí tienen palabras distintas en inglés: legibility, que estos autores traducen como algo aproximado a "visibilidad" (que una letra se vea mejor o peor), y readability, "que podríamos interpretar como 'lecturabilidad' -si la palabra existiera en castellano- o fácil de leer, legible”.

Para el estudioso francés en el tema de la legibilidad existen ocho factores que intervienen en lo que él denomina "legibilidad tipográfica" (Richaudeau, 1984: 13-24), y que diferencia de la "legibilidad lingüística" referida a los textos, "a la elección de las palabras y sus combinaciones en el seno de las frases". Estos factores serían el tamaño de los caracteres; los espacios entre palabras; la justificación de las líneas o bien su alineación a la izquierda, centro o a la derecha; la longitud de las líneas; el espaciado entre ellas o interlínea; y las tintas y el papel que sirve de soporte. Según los estudios cuantitativos norteamericanos antes mencionados en los que se apoya el autor francés, el diseño de las letras no tiene incidencia alguna en la legibilidad, entendida ésta como la velocidad a la que se puede leer un texto. Tan sólo el espaciado entre letras y, sobre todo, el tamaño de los caracteres, influyen, aunque tampoco de gran manera. El único elemento que cita Richaudeau como decisivo en lo que a facilidad de lectura se refiere es "el hábito" de leer en unos caracteres o en otros, y cita precisamente a los caracteres góticos como ejemplo: "Un texto compuesto en caracteres góticos [incluye aquí los caracteres a, b, c, d, e, en letra gótica] será leído malamente por un francés o un inglés, y fácilmente por un universitario alemán” (1984: 15). Afirmación que ponemos en duda porque los libros que se publican actualmente en Alemania no utilizan tipografías góticas a lo que hay que sumar el hecho que destaca Yvonne Schwemer-Scheddin de que la letras gótica "ya no se enseña en los colegios y, así, es muy difícil de leer" (en Bain y Shaw, 2001: 91), o el dato que aporta Hans Peter Wilberg de que desde 1941 
"todo lo impreso tuvo que adaptarse a la romana: los libros de texto fueron sustituidos y, en la escuela, debía ponerse en práctica la enseñanza exclusiva de la escritura manual latina” (en Bain y Shaw, 2001: 76-77). Es muy distinto un letrero, un cartel, rotulaciones de distinto tipo, que un texto seguido en cuerpos pequeños. Coinciden también Bertheau en el uso o costumbre como factor esencial en la legibilidad de los tipos de letra, "característica que no puede medirse o demostrarse con métodos científicos, puesto que, en primer lugar, el lector debe estar familiarizado con las convenciones que permiten leer el texto" (en Bain y Shaw, 2001: 45); o Philipp Luidl en la misma obra de referencia, quien tras hablar primero de "estar familiarizado" llega después a un argumento que contradice esta tesis del uso o costumbre, cuando afirma que si "la legibilidad depende de la capacidad de distinguir los contornos de la palabra con facilidad, podemos afirmar que la gótica de fractura ofrece mucha más riqueza que los tipos romanos" (en Bain y Shaw, 2001: 39).

Desde el punto de vista cualitativo, la opinión de los más importantes tipógrafos y diseñadores relaciona la legibilidad de los tipos de letra con elementos como el contraste entre las distintas partes de un carácter, el ojo medio (también llamado "altura de la x", y que equivale a la medida vertical de una letra minúscula sin rasgos ascendentes y descendentes), y las contraformas, elemento al que cada vez se le otorga un mayor protagonismo en el diseño de un alfabeto y que se refiere a los espacios blancos encerrados en el interior de los caracteres, el círculo interno inscrito en la circunferencia que dibuja una "o" como ejemplo más claro. Estos tres elementos en el caso de las tipografías góticas frente a las romanas (Times New Roman, es el representante moderno más importante de este grupo de tipografías) son un claro ejemplo de su menor legibilidad. La tipografía gótica tiene un excesivo contraste entre las distintas partes de una misma letra, su ojo medio es muy grande pero se desdibuja precisamente por la complicación e incluso la ausencia de las contraformas. En lo que sí coinciden ambos planteamientos, cuantitativos y cualitativos, es en el hábito. Eric Gil afirmaba que "en la práctica, la legibilidad equivale a lo que uno está acostumbrado".

Vamos al Renacimiento. Nicolas Jenson, grabador francés que había aprendido el arte de la impresión con el mismo Gutenberg en Maguncia -se atribuía a sí mismo la invención de la imprenta- se afincó en 1468 en Venecia, donde creó el que está considerado como el primer tipo de letra romana para la impresión. Se inspiró para las letras minúsculas en una fusión de la anterior escritura denominada carolingia con "la lettera antica, un estilo manuscrito clásico con formas más anchas y abiertas" (Lupton, 2016: 15), y para las letras mayúsculas en los caracteres lapidarios de los monumentos de la antigua Roma clásica. Los tipos de Jenson son de una belleza y una perfección formal que sólo superarán poco tiempo después los creados como una evolución de los suyos por uno de los tipógrafos, además de editor y escritor humanista, más grande de todos los tiempos, Aldo Manuzio.

Si hay alguien que encarne el ideal del humanismo y del Renacimiento es sin duda este hombre singular que se propuso "regenerar la sociedad a través de la cultura" (Satué, 1998: 67), lema publicitario de su taller de imprenta. Con la ayuda económica de la familia de su amigo y condiscípulo, Pico della Mirandola, pudo instalarse en Venecia en 1490. Allí se asoció con el empresario editor Andrea Torresani, quien había adquirido los tipos de letra y el taller de imprenta de Jenson a su muerte, junto con quien tallaba los punzones, Francesco Griffo. Del taller de Aldo salieron impresos los libros más codiciados en toda Europa. Tanto por sus contenidos, ya que rescató obras en griego y latín fundamentales de la cultura clásica, para las que tuvo que crear tipografías en caracteres griegos, como por la calidad de la impresión. El mismo Erasmo 
de Rotterdam elogió las tipografías de Manuzio e incluso pasó un año en su casa de Venecia para supervisar, y admirar, la impresión de alguna de sus obras.

Para editar el primero de sus libros en latín, Sobre el Etna (1495), de Pietro Bembo, Manuzio y su grabador Griffo crearon un tipo de letra que superó los magníficos caracteres de Jenson. Un tipo del que todos los contemporáneos hablan de su "claridad", referida posiblemente a lo que ahora llamamos legibilidad. Claridad y belleza en insuperable armonía. Tanta que ese tipo de letra se sigue utilizando actualmente con el nombre de Bembo, rescatada por el tipógrafo Stanley Morison en los años veinte del siglo pasado para la empresa norteamericana Monotype. Con estos tipos de letra, aunque modificados en busca de una imposible perfección, Manuzio editó en 1499 uno de los últimos incunables: Hypnerotomachia Poliphili (El sueño de Polifilo), obra mítica considerada por algunos bibliófilos como el libro más bello jamás impreso. Y es que, tal y como analiza Benjamin en su obra antes citada, la reproductibilidad confiere a la obra de arte, a cualquier objeto cultural o del ámbito que sea, una cualidad imposible antes de que la técnica posibilitara su reproducción: "su capacidad de ser mejorada" (2003: 61). Y es eso lo que hace una y otra vez Aldo Manuzio con los tipos de letra, a pesar del elevadísimo coste que supone, en tiempo y dinero, fundir nuevas pólizas completas de caracteres.

Pero la fama y el prestigio de los que gozó en vida Manuzio, y es de suponer que el dinero, no le llegaron con el libro más bello que nunca se hubiera impreso sino con la colección de clásicos que lanzó al mercado en el denominado formato "en octavo". Es el primer impresor en utilizar este tamaño de páginas para la literatura, muy pequeño en aquel momento -la octava parte del pliego de imprimir, unos dieciocho centímetros de alto-, originalidad que está considerada como la invención del libro de bolsillo. Para estos libros, diseñó junto a Griffo un tipo de letra que entonces denominaron 'aldina' en honor a su creador, y que ahora denominamos cursiva. Aquello fue una genial y arriesgada idea que cambió los hábitos de lectura y el consumo de libros en toda Europa. Existen infinidad de retratos al óleo de ricos burgueses del momento que aparecen con uno de esos libros pequeños en una de sus manos como símbolo de prestigio cultural. Si mencionábamos antes el "hábito" como uno de los factores determinantes de la legibilidad de un tipo de letra, ahora que los caracteres impresos viajaban por todas las ciudades de Europa, las tipografías góticas perdieron pues su primera batalla ya que fuera de Alemania, de los círculos eclesiásticos, o de los impresos oficiales revestidos de solemnidad, la mayor parte de los nuevos lectores no estaban acostumbrados a aquellas letras tan difíciles de leer. Además, las tipografías humanistas encarnaban y transmitían el sistema de valores de la nueva sociedad, del nuevo sistema de pensamiento. Satué afirma al respecto que el asunto estaba "listo para sentencia" y cita la autoridad del experto en libros impresos del siglo XV George Painter:

La Biblia de 42 líneas de 1455, y la Hypnerotomachia o El sueño de Polifilo, de 1499, configuran ellas solas el período incunable de una manera preeminente, una al principio y otra al final. La Biblia de Gutenberg es sombría y severamente germana, gótica, cristiana y medieval; la Hypnerotomachia, en cambio, es radiante y gozosamente italiana, clásica, pagana y renacentista. Ambas son las más extraordinarias obras maestras del arte de la imprenta, situadas en los dos polos de las aspiraciones y los deseos humanos (1998: 146-147).

A pesar de que los caracteres góticos tuvieron un gran impulso en Alemania con la publicación de la Biblia traducida al alemán por Lutero en 1534, compuesta en tipografía schwabacher (Batheau incide en que Lutero seleccionó el tipo de letra en clara oposición a los tipos romanos asociados ya entonces al papado [en Bain y Shaw, 2001: 45-50]), en lo que respecta 
al resto del conteniente la tipografía gótica había perdido la primera de sus batallas, pero como recuerda Walter Benjamin, el valor ritual de los objetos culturales "no cede sin ofrecer resistencia" (2003: 58).

\section{La segunda batalla (Gótica versus Futura)}

Poco antes de que los nazis llegasen al poder en Alemania en enero de 1933, Paul Schultze-Naumburg, arquitecto y miembro fundador del Werkbund -Deutscher Werkbund, Liga alemana del trabajo, organización creada en 1907 en Múnich centrada en la arquitectura y el diseño, precursora en cierto sentido de la Bauhaus- organizó una serie de conferencias por toda Alemania para difundir sus teorías sobre el arte y el diseño relacionados con la raza. En la ciudad de Múnich tuvo tal éxito que se vio obligado a repetir la sesión días después. En su ponencia presentaba diapositivas sobre arte moderno, arte asiático y africano, en las que él veía el "producto de una mente perversa" (Burke, 2000: 125), un precedente de la famosa exposición celebrada también en Múnich en 1937 con el título de Arte degenerado. En la segunda conferencia de Schultze-Naumburg en Múnich, un joven pintor de la ciudad, Wolff Panizza, tuvo la osadía de preguntar dónde estaba entonces el buen arte moderno y la respuesta que recibió fue una brutal paliza por parte de los guardias nazis que custodiaban la conferencia. Le patearon el estómago con sus botas y le destrozaron la cara con sus puños de hierro para que así, en el hospital, tuviese "tiempo de reflexionar sobre su pregunta y la respuesta recibida" (2000: 125).

El incidente quedó reflejado en el folleto Kulturbolschewismus? (¿Cultura bolchevique?), publicado en 1932 por el tipógrafo y miembro destacado también del Werkbund Paul Renner, un escrito que le costó además de su detención, su cargo como director de la Escuela de Maestros Impresores de Alemania en Múnich. Poco antes de su detención, el 31 de marzo de 1933, había recibido una visita en su despacho de un alto funcionario del Ministerio de Asuntos Exteriores para supervisar el trabajo como comisario que estaba haciendo Renner para la exposición internacional destinada a la V Triennale de Milán. "Se consideró que varios objetos no eran correctos" y Hanfstaengl (director de la Galería Nacional de Berlín) "se quejó específicamente de que la muestra estaba desequilibrada a favor de los tipos de letra romanos en perjuicio de los góticos" (2000: 130).

La mencionada asociación del Werkbund, se inspiró en sus comienzos en el movimiento inglés Arts and Crafts de William Morris. Una corriente de pensamiento que preconizaba una vuelta al trabajo manual, al hombre frente a la máquina, ante la creciente deshumanización que acarreaba el proceso de industrialización en los últimos años del siglo XIX y comienzos del XX. El Arts and Crafts inglés impulsó de un modo extraordinario la tipografía y todo lo relativo a la impresión de libros, carteles y artes gráficas en general. Uno de sus continuadores más importantes fue Stanley Morison, creador de la tipografía Times New Roman, caracteres romanos en su más decantada expresión y uno de los tipos de letra de mayor éxito en toda la historia. La realizó además para rediseñar por completo el periódico The Times -está considerado el primer rediseño completo de un periódico, tipografía incluida-, que salió impreso el lunes 3 de octubre de 1932 con estos flamantes caracteres ya inmortales. Sin embargo, el movimiento alemán del Werkbund tenía algunas características diferenciadas, entre las que destaca que más que ir en contra de la industrialización, su propuesta era la de armonizar ambas facetas, industria y arte, reconciliar la manufactura artesanal de calidad con la producción en serie. "En el debate sobre la tecnología, la máquina se convirtió en el tema principal de la lucha entre tradicionalismo y vanguardia” (Burke, 2000: 26). 


\section{Ietrås gúticns letras Futura}

Figura 2. Tipografía gótica Fraktur (arriba) y tipografía Futura diseñada por el alemán Paul Renner en 1927 (abajo).

En este contexto de tensiones entre tradición y modernidad, surge también en Múnich y con los tipógrafos Paul Renner y Jan Tschichold como figuras destacadas, el movimiento denominado Nueva Tipografía. Aunque el término lo acuñó Moholy-Nagy para el catálogo de la histórica exposición de la Bauhaus de 1923, los teóricos más importantes fueron el mencionado Tschichold, fundamentalmente en su obra del mismo nombre Die Neue Typographie, (Nueva Tipografía) de 1928, así como el propio Paul Renner con su Mechanisierte Grafik (Diseño gráfico mecanizado), publicado en 1931. Los principios de la Nueva Tipografía pueden resumirse en la simplicidad y sencillez, la ausencia absoluta de toda ornamentación, el llamado diseño asimétrico (textos alineados siempre a la izquierda en vez de centrados como sucedía de manera clásica con los títulos), y la utilización de tipos de palo seco (sin remate o sans serif), como la tipografía Futura que durante aquellos años estaba desarrollando el mismo Renner. Es un diseño gráfico muy relacionado con la arquitectura, con el funcionalismo (aunque menos radical en sus planteamientos en este sentido que en el caso de la Bauhaus) y con la vanguardia. En relación a la Bauhaus hay autores, como el propio Burke (2000: 59), que sostienen que se ha sobrevalorado históricamente a la Escuela de Artes y Oficios de Weimar en lo relativo al diseño gráfico y la tipografía, puesto que todas sus propuestas son en realidad obra de la Nueva Tipografía de Múnich, pero que debido al exilio de las principales figuras de la Bauhaus a los Estados Unidos como consecuencia del nazismo, tuvieron más difusión internacional.

En el verano de 1924, Paul Renner realizó los bocetos de un tipo de palo seco-“la reina del 'palo seco'”, según Satué (2007)-, de inspiración geométrica, utilizando la simetría pura y las figuras elementales (círculo, cuadrado y triángulo), animado por Jakob Hegner, director de una industria editorial y de artes gráficas, que buscaba un tipo de letra moderno de aquellas características. En 1927 concluyó el diseño de la letra que lanzó al mercado la fundición tipográfica Bauer de Frankfurt. El resto es historia porque se trata sin duda de un tipo de letra que ya se ha convertido en un clásico del siglo XX, junto a la Times de Morison en 1932, y la Helvética de Miedinger y Hofman en 1957. Señala Burke que las primeras palabras que escribió, dibujó literalmente, Paul Renner con su nuevo tipo de letra en aquel verano de 1924 fueron Die Schrift unserer Zeit (el tipo de letra de nuestra época), un lema que acompañó posteriormente el lanzamiento comercial de la tipografía Futura (2000: 82). Aquello implicaba que su tipografía surgía del Zeitgeist (el espíritu de un tiempo), lo que parecen corroborar autores como Satué, cuando afirma que "sin duda, la Futura fue el más característico retrato del periodo racionalista” (Satué, 2007: 42). Pero no sólo fue eso, ya que Renner también insistió durante toda su vida en que aquel alfabeto era, nada más y nada menos, que el tipo de letra de Alemania.

La identidad nacional o el "espíritu de una época" se construyen, pues, de esta forma, a través de lenguajes entre los que está sin duda el lenguaje visual de la tipografía, motivo por el cual los tipos modernos de Renner se enfrentaron a los tipos 
tradicionales góticos a los que se aferraron los nazis en un primer momento para identificarse así con lo "genuinamente alemán". "El tipo de letra es uno de los más elocuentes medios de expresión de cada época y estilo", manifestó Peter Behrens, arquitecto, interiorista, pintor, grabador y diseñador, además de miembro también del Werkbund, "próximo a la arquitectura, proporciona el retrato más característico de un periodo y el testimonio más severo del nivel intelectual de un país" (Satué, 2007: 28). Una opinión compartida por la inmensa mayoría de los tipógrafos e incluso por los encargados de recrear otras épocas, quienes utilizan para ello con mucha frecuencia la tipografía, los impresos y carteles de cada momento histórico. Como Ellen Lupton que, además del carácter histórico -cuando menciona "la tradición en curso que te conecta con otros diseñadores, pasados y futuros" (2016: 8)-, inscribe además a la tipografía en un "flujo social de mensajes" determinado por el tipo de letra que se escoja para elaborarlos:

Cuando escogen un tipo de letra, los diseñadores gráficos tienen en cuenta la historia de la tipografía, sus connotaciones actuales y sus cualidades formales. El objetivo es dar con una buena sintonía entre el estilo de las letras, la situación social específica y el contenido del proyecto que les ocupa (2016: 32).

Por todo esto, no es de extrañar que en el contexto histórico descrito, los nazis se apropiaran de las letras góticas como un elemento de "identidad nacional" en su propaganda. Hay antecedentes: en 1813 con la invasión napoleónica, en la guerra franco-prusiana de 1870 o en 1914, en los prolegómenos de la I Guerra Mundial, cuando la tipografía gótica, "el tipo alemán, se impregnó de nacionalismo" (Willberg, en Bain y Shaw, 2001: 71). También menciona Satué a ese otro maestro de la manipulación desde el poder que fue el cardenal Richelieu en el siglo XVII, creador y organizador de la Imprenta Real Francesa, "consciente de la importancia de la tipografía como instrumento de gobierno y propaganda" (2007: 27). En el caso de la Alemania de los años treinta del siglo XX, si los responsables de comunicación (propaganda en aquel tiempo) del partido Nacional Socialista asociaban las virtudes históricas de un pueblo alemán ideal a un tipo de letra determinado y los panfletos y comunicados del partido utilizaban ese mismo tipo de letra -la propia cubierta del Mein Kampf (1925) de Hitler fue compuesta en tipos góticos-, se estaba reforzando el mensaje de una forma que además resulta en cierto modo "invisible", pese a la aparente paradoja de que hablamos de lenguaje visual. Precisamente, cuando Mauro Wolff habla de "la formación de la cultura" se refiere a la forma en la que se estructura el conocimiento y la conciencia, y por ello:

Los que lo experimentan tienden a ser inconscientes, exactamente del mismo modo en que no se es consciente de la formación del conocimiento o no se está atento al propio hecho de estar atento a algo (...). Esto no quiere decir que esta clase de proceso sea invisible, sino más bien que se tiene que convertir en invisible, porque su invisibilidad es una condición de su eficacia (1994: 118-119).

Y es ese tipo de invisibilidad como condición para la eficacia la que impulsó el uso de la tipografía por parte de los jerarcas nacionalsocialistas. Una forma de actuar que, por otro lado, Viktor Klemperer atribuye en general a todo su discurso. En su libro LTI. La lengua del Tercer Reich, publicado en 1947, Klemperer habla de "pobreza de la esclavitud uniformada", "retahíla de tópicos", o "lenguaje del fanatismo de masas" en relación con los discursos de las autoridades de la Alemania nazi. Su análisis sitúa los elementos extralingüísticos de la LTI, especialmente los discursos del propio Hitler, prácticamente al mismo nivel que los contenidos de sus palabras: frases cortas y pobres en las que destaca el volumen, las inflexiones de la voz, etc. Elementos que podemos equiparar en el lenguaje escrito con la tipografía. Y es que con la tipografía se puede mentir: 
Signo es cualquier cosa que pueda considerarse como substituto significante de cualquier otra cosa. Esa cualquier otra cosa no debe necesariamente existir ni debe subsistir de hecho en el momento en el que el signo la represente. En este sentido, la semiótica es, en principio, la disciplina que estudia todo lo que pueda usarse para mentir (Eco, 2000: 22).

Ya hemos mencionado que cuando hablamos de letras góticas nos referimos en realidad a un conjunto de varios tipos de letras con características comunes (forma, suma, schwabacher, fraktur) que según autores como Luidl (en Bain y Shaw, 2001: 37-43) se adaptarían a las propias características de la lengua hablada alemana (su mayor énfasis en las palabras como unidad sonora más que en una estructura silábica, o el predominio de sonidos consonantes), "y el tipo es el idioma visible" (Shaw y Bain, 2001: 32). Tipos de letras asociados fundamentalmente desde la reforma luterana a la cultura alemana pero que el propio Paul Renner puntualizó señalando su auténtico origen:

Siempre que se hiciera referencia al estilo gótico, también en el caso de la letra gótica, se debería sustituir el término gótico por franco, puesto que el estilo gótico no es el de los godos sino el de los francos. La minúscula carolingia sufrió una transformación estilística antes de convertirse en el tipo universal: el arco de medio punto se convirtió en arco ojival (2000: 233).

Así que lo que proclamaba Renner era nada más y nada menos que aquellos tipos de letra que encarnaban el espíritu alemán... jeran de origen francés! Francés, que como es bien sabido, es el enemigo antagonista de lo alemán por antonomasia. Por eso, insistía en que el suyo, la Futura, sí era un tipo de letra absolutamente alemán. Y tenía razón. Pero no la capacidad de acabar con una tradición tan arraigada. Fue una vez más el enemigo irreconciliable de la letra gótica, la falta de legibilidad, lo que se convirtió en arma determinante para que perdiese ésta su segunda batalla. Con la expansión internacional que tenía en mente Hitler, aquellos caracteres resultaban inútiles para comunicar normas a los pueblos ocupados, porque como ya hemos visto antes, el hábito a unos caracteres, la costumbre, es determinante para leer con más o menos facilidad un tipo de letra, y en ningún país excepto Alemania se leían de forma general textos en caracteres góticos en pleno siglo XX. El 3 de enero de 1941 -firmado el año anterior el pacto con Italia y Japón para instaurar el nuevo orden mundial, y habiendo ocupado ya parte de Francia, los Países Bajos, Bélgica, Dinamarca y Noruega-, como señala Burke, se publicó un decreto del gobierno alemán en el que se prohibía la escritura gótica con el delirante argumento de que se trataba de "letras judías" (2000: 167). Tan delirante, que el decreto se divulgó escrito a máquina con el membrete del partido nazi compuesto en tipos góticos. El nuevo "relato" para justificarlo era que al parecer los judíos se habían hecho en tiempos pasados con la propiedad de muchas de las imprentas alemanas para así inocular su cultura... y sus tipos de letra.

\section{Conclusiones: las formas de los signos son las formas del mundo}

Entendemos con Nietzsche que no existe un funcionamiento "no retórico" del lenguaje (puesto que lo que solemos llamar "retórica" remite ni más ni menos que al conjunto del aparato normativo y conceptual del lenguaje, a la gramática y al pensamiento) por lo tanto no podemos compartir las reflexiones que resuelven y finiquitan la cuestión de la tipografía y el sentido como un problema de persuasión. La tipografía tiene una función comunicativa constructiva, estética, didáctica y persuasiva en el sentido de que desea ser leída y acompañar en coherencia el contenido, pero decir esto no implica poder describir cuáles son los mecanismos que explican que un tipo de letra se asocie y contribuya a la construcción de un dis- 
curso social determinado. Pensamos que nuestra propuesta, centrada en la idea de que el significado de un signo no está dado por su objeto sino por su interpretación, son los efectos que produce, es más esclarecedora.

El signo posee la capacidad de permitir varias, todas, las miradas sobre el objeto pero sólo activa una, aquella que muestra el aspecto habitualizado, el sentido dominante estabilizado. Y los ejemplos mostrados suponen una constatación. Las formas y las leyes de nuestros mundos no se encuentran ahí sino que viene impuestas por nuestras versiones del mundo y las formas, los signos, que empleamos para pensar y nombrar esas versiones determinan las formas del mundo. Saber lo que significan las palabras de un lenguaje (forma y contenido) es captar la manera en que son usadas, es decir, cómo se fijan las creencias que contienen esas palabras. El significante apunta un relato que es mediador en el sentido de nuestra relación con el mundo y de nuestra relación con la palabra que lo soporta. La tipografía es un procedimiento epistémico, un modo de conocer y a la vez una práctica legitimante de aquellos relatos que incorpora. Su lectura no es inocente, parece hacernos sus partidarios. Usar o interpretar un tipo nos hace tomar partido..

\section{Referencias bibliográficas}

Abril, G. (2003). Cortar y pegar. La fragmentación visual en los orígenes del texto informativo. Madrid: Cátedra.

-(2005). Teoría general de la información. Datos, relatos y ritos. Madrid: Cátedra.

- (2012). Tres dimensiones del texto y la cultura visual. IC - Revista científica de información y comunicación (9), pp. 15-35.

Bain, P. y Shaw, P. (2001), coord. La letra gótica. Tipo e identidad nacional. Valencia: Campgràfic.

Bann, D. (2008). Actualidad en la producción de artes gráficas. Barcelona: Blume.

Barthes, R. (1999). Mitologías. Madrid: Siglo XXI.

Benjamin, W. (2003). La obra de arte en la época de su reproductibilidad técnica. México: Editorial Ítaca.

Burke, Ch. (2000). Paul Renner, maestro tipógrafo. Valencia: Campgràfric.

Dondis, D. A. (2014). La sintaxis de la imagen. Introducción al alfabeto visual. (17a ed., edición original de 1973) Barcelona: Gustavo Gili.

Eco, U. (2000). Tratado de semiótica general. Barcelona: Lumen.

Farias, P. L. (2016). Semiótica e tipografia: apontamentos para un modelo de anàlise en MORAES, D., DÍAS, R. y SALES R. (Org.) Cadernos de Estudos Avançados em Desing: Desing e Semiótica. Barbacena: EdUEMG, pp. 45-56.

Gamonal, R. (2012). Tipo/retórica. Una aproximación a la retórica tipográfica. ICONO14. Revista científica de Comunicación y Tecnologías Emergentes, 3(1), pp. 75-97. Recuperado el 7 de enero de 2018 desde https://iconol4.net/ojs/index.php/ icono14/article/view/430.

González Díez, L. y Pérez Cuadrado, P. (2001). Principios básicos sobre diseño periodístico. Madrid: Editorial Universitas.

-(2007). Treinta años de diseño periodístico en España (1976-2006). Madrid: Zona Impresa.

Grupo $\mu$ (1997). Retórica general. Barcelona: Paidós. 
Cómo grita la tipografía. Procesos de mediación cultural y condición de lo visible

Jardí, E. (2007). Veintidós cosas que nunca debes hacer con las letras (que algunos tipógrafos nunca te dirán). Veintidós consejos sobre tipografía (que algunos diseñadores jamás revelarán). Barcelona: Actar.

Jobs, S. (2005) recuperado el 14 de septiembre de 2018 desde https://www.youtube.com/watch?v=vXJYrrLGNAo.

Klemperer, V. (2001). LTI. La lengua del Tercer Reich. Barcelona: Editorial Minúscula.

Lupton, E. (2016). Pensar con tipos. Barcelona: Gustavo Gili.

Martín Montesinos, J.L. y Mas Hurtuna, M. (2007). Manual de tipografía, del plomo a la era digital.Valencia: Campgràfic.

Morison, S. (1998). Principios fundamentales de la tipografía. Barcelona: Ediciones del Bronce.

Renner, P. (2000). El arte de la tipografía (ed. original Die Kunst der Typographie, Berlín, 1939). Valencia: Campgràfic.

Richaudeau, F. (1984). La legibilidad. Investigaciones actuales. París: Fundación Germán Sánchez Ruipérez.

Sanchez Leyva, M. J. (2010). Jeroglíficos contemporáneos. Las redes indicales como dispositivos culturales masivos en ICRevista Científica de Información y Comunicación, (7), pp. 89-110.

Satué, E. (1998). El diseño de libros del pasado, del presente, y tal vez del futuro. La huella de Aldo Manuzio. Madrid: Fundación Germán Sánchez Ruipérez.

-(2007). Arte en la tipografía y tipografia en el arte. Madrid: Siruela.

Serra y Oliveres, A. (1852). Manual de la tipografía española o arte de la imprenta. Madrid: Librería de D. Eduardo Oliveres. Thompson, J.B. (2010). Los media y la modernidad. Una teoría de los medios de comunicación. Barcelona: Paidós.

Tschichold, J. (2002). El abecé de la buena tipografia. Valencia: Campgràfic.

Vílchez, J. F. (2011). Historia gráfica de la prensa diaria española (1758-1976). Barcelona: RBA.

Wolff, M. (1994). Los efectos sociales de los media. Barcelona: Paidós. 